\title{
Influências da espiritualidade e religiosidade na assistência de enfermagem a pacientes que facejam o processo morte-morrer
}

\section{Influences of spirituality and religiosity in nursing care to patients facing the death-dying process}

Las influencias de la espiritualidad yreligiosidade en los cuidados de enfermería a los pacientes que llevan el proceso de muerte-morrir

\author{
Marcela Teixeira de Souza1, Camila Araujo Nascimento², Renê dos Santos Spezani ${ }^{3}$
}

Como citar esse artigo. de Souza, MT; Nascimeno, CA; Spezani, RS. Influências da espiritualidade e religiosidade na assistência de enfermagem a pacientes que facejam o processo morte-morrer. Revista Pró-UniverSUS. 2019 Jul./Dez.; 10 (2): $32-38$

\begin{abstract}
Resumo
Objetivo: Consiste em compreender como a inclusão da espiritualidade e da religiosidade na assistência de enfermagem influenciam o tratamento de pacientes que facejam o processo de morte-morrer. Metodologia: Trata-se de revisão integrativa com abordagem qualitativa e natureza exploratória. A coleta de dados foi realizada na Biblioteca Virtual em Saúde, a partir de produções socializadas nos últimos cinco anos. A amostra constituiu-se de treze artigos que melhor se articularam com o objetivo do estudo. Resultados: Verifica-se a existência de variados estudos estabelecendo relações entre enfermagem, espiritualidade, religiosidade e cuidados paliativos na assistência em saúde. O paciente que recebe cuidados paliativos é um paciente sensível que tende a sentir maior carência espiritual e religiosa. Contudo, ainda existe uma dificuldade dos profissionais para lidar com essa questão. Conclusão: Apesar de não haver solução para a morte, é possível proporcionar um processo de terminalidade digno, para o qual é fundamental o apoio emocional e a valorização da espiritualidade e da religiosidade na assistência de enfermagem em cuidados paliativos.
\end{abstract}

Palavras-chave: Cuidados Paliativos, Enfermagem, Espiritualidade, Religiosidade.

\begin{abstract}
Objective: It consists understanding in how the inclusion of spirituality and religiosity in nursing care influences the treatment of patients facing the death-dying process. Methods: It's an integrative review with qualitative approach and exploratory nature. The data collection was performed in the Virtual Health Library from socialized productions in the last five years. The sample consisted ofthirteen articles that articulated the best with the purpose of the study. Results: There are several studies establishing relationships between nursing, spirituality, religiosity and palliative care in health care. The patient who receives palliative care is a sensitive patient that tends to experience a greater spiritual and religious need. However, there is still a difficult for the professionals to deal with this issue. Conclusion: Although there isn't a solution to death, it's possible to provide a decent terminal process, for which is fundamental the emotional support and the valorization of spirituality and religiosity in nursing care in palliative care.
\end{abstract}

Keywords: care, Nursing, Spirituality, Religiosity.

\section{Resumen}

Objetivo: Consiste en comprender como la inclusión de la espiritualidad y de la religiosidad em los cuidados de enfermería influencian en el tratamiento a los pacientes que llevan el proceso de muerte-morrir. Metodología: Se trata de una revisión integradora con abordaje cualitativa y naturaleza exploratoria. La colecta de los datos fue realizada en la Biblioteca Virtual en Salud, a partir de producciones socializadas de los últimos cinco años. La muestra fue constituida por treceartículos que mejor articularon con el objetivo del estudio. Resultados: Se verifica la existencia de variados estudios estableciendo relaciones entre enfermería, espiritualidad, religiosidad y cuidados paliativos en la asistencia de la salud. El paciente que recibe los cuidados paliativos es un paciente sensible que tende a sentir una mayor carencia espiritual y religiosa. No obstante, aún existe una dificultad para los profesionales para lidiar con esta cuestión. Conclusión: A pesar de que no haga solución para la muerte, es posible proporcionar um proceso de terminalidad digna, en lo que es fundamental el apoyo emocional y la valorización de la espiritualidad y de la religiosidad em la asistencia de enfermería en los cuidados paliativos.

Palabras clave: Cuidados Paliativos, Enfermería, Espiritualidad, Religiosidad.

Afiliação dos autores: 1. Acadêmica de Enfermagem, Centro Universitário Augusto Motta, Rio de Janeiro, RJ, Brasil. Email: marceelateeixeira@gmail.com ORCID: https://orcid. org/0000-0001-9630-1112

2. Acadêmica de Enfermagem, Centro Universitário Augusto Motta, Rio de Janeiro, RJ, Brasil. Email: caah.roxy@live.com ORCID: https://orcid.org/0000-0002-6782-9425

3. Pós-doutorando em Enfermagem - UERJ. Professor do Centro Universitário Augusto Motta, Rio de Janeiro, RJ, Brasil. Email: renespezani@gmail.com ORCID:Orcid: https:// orcid.org/0000-0002-5347-6112 


\section{Introdução}

Percebe-se que a doença gera um grande impacto na vida do ser humano. Quando se trata de uma doença em estágio terminal, há uma forte comoção emocional, não só para paciente, mas para todos aqueles que estão ao seu lado ${ }^{1}$.

$\mathrm{O}$ cuidado paliativo teve início no século XX, com Cecily Saunders e alguns colaboradores ao organizarem o movimento hospice, que difundiu pelo mundo uma filosofia com dois elementos fundamentais sobre o cuidar. O primeiro foi o controle efetivo da dor e de outros sintomas, e o segundo foi o cuidado com as dimensões psicológicas, socias e espirituais de pacientes e seus familiares ${ }^{2}$.

Por sua vez, verifica-se que pesquisas científicas recentes têm revelado que a espiritualidade e prática religiosa mostram resultados positivos sobre a saúde mental, e não podem mais ser ignoradas ou excluídas do escopo dos estudos, tampouco serem taxadas como componentes irrelevantes da práxis de enfermagem ${ }^{3}$.

$\mathrm{Na}$ enfermagem, a partir da Teoria do Cuidado Humano de Jean Watson, torna-se possível exemplificar a importância dessa atividade nos cuidados de enfermagem. Segundo a Teoria do Cuidado Humano proposta por Jean Watson, deve-se atribuir grande importância ao treinamento em Ciências Humanas, aspecto muito esquecido na formação do enfermeiro, por ser capaz de fornecer ferramentas essenciais para o entendimento da dinâmica social, cultural e psicológica dos indivíduos ${ }^{3}$. Jean Watson, em sua teoria, apresenta dez preceitos que ampliam os horizontes do cuidado, para além do espectro biológico, com maiores possibilidades de contemplar, com a devida coerência e eficácia, as reais necessidades do ser humano, e entre eles está presente e se destaca a valorização das crenças do ser que está sendo cuidado.

Porém, a realidade verificada, tanto nas experiências particulares dos pesquisadores quanto em grande parte das pesquisas que versam sobre o processo de morte e morrer ratificam queo enfrentamento da terminalidade e da finitude é uma árdua tarefa para o paciente, familiares e para os profissionais de saúde que o acompanham, fato que vem, sobremaneira, estimulando a realização de um número cada vez maior de novos estudos envolvendo a espiritualidade e religiosidade no campo dos cuidados paliativos na atualidade.

Nesse contexto, torna-se possível destacar também que o convívio com pessoas que recebem cuidados paliativos oportuniza aos profissionais o reconhecimento dessas vivências, que no fundo, também culminam por caracterizar excelentes experiências de aprendizagem. Isso, considerando que muito embora se reconheça a importância da dimensão espiritual no atendimento de pacientes sob cuidados paliativos, ainda é grande o despreparo para lidar com as questões que envolvem a dimensão espiritual e religiosa ${ }^{4}$.

Esse panorama, aliado à intenção de aprofundamento sobre as temáticas em destaque, motivaram e justificam a realização desse estudo, cujo objetivo consiste em compreender como a inclusão da espiritualidade e da religiosidade na assistência de enfermagem influencia o tratamento de pacientes que facejam o processo de morte e morrer.

\section{Metodologia}

Trata-se de revisão integrativa com abordagem qualitativa e natureza exploratória. A coleta de dados foi realizada na Biblioteca Virtual em Saúde (BVS). Para tanto, recorreu-se aos bancos de dados da Literatura Latino Americana e do Caribe em Ciências e Saúde (LILACS), Scientific Electronic Library Online (SCIELO) e Base de Dados de Enfermagem (BDENF), por meio do emprego dos descritorescuidados paliativos; enfermagem; espiritualidade ereligiosidade.

Esse movimento de busca foi mediado a partir de critérios de inclusão e exclusão previamente estabelecidos, sendo selecionadas as produções socializadas nos últimos cinco anos, publicadas no idioma português e disponibilizadas de forma completa para leitura. Além das produções que não se enquadravam nesses critérios preliminares, também foram excluídas da pesquisa aquelas que se repetiam nas bases de dados consultadas e/ou aquelas que não estabeleciam articulações com seu objetivo.

Dessa forma, a amostra de produções selecionadas para leitura e análise constituiu-se de 13 produções que melhor se articularam com o objetivo desse estudo. Diante do material selecionado, procedeu-se à análise compreensiva, articulando-se o pensamento dos autores ao dos pesquisadores de maneira crítico-reflexiva, possibilitando a interpretação e análise dos dados, bem como o alcance do objetivo proposto no estudo.

\section{Resultados e Discussão}

As 13 produções selecionadas para análise e interpretação constituíram a Bibliografia Potencial, expressa no Quadro 1.

Diante das produções científicas selecionadas, verifica-se a existência de variados estudos estabelecendo relações entre enfermagem, espiritualidade, religiosidade e cuidados paliativos na assistência em saúde.

Primeiramente, é importante ressaltar que a espiritualidade se difere de religiosidade. A espiritualidade é a relação entre o sujeito e algo que transcende o conceito de materialidade, que é toda ou qualquer ligação com algo "divino". A religiosidade, por sua vez, é a crença em uma religião específica, 
caracterizada em dogmas, hierarquias, livros sagrados e rituais, dentre outros aspectos ${ }^{5}$.

Nota-se assim que a espiritualidade pode abranger mais pessoas, mesmo que para isso não possuam uma religião específica, uma vez que as desobriga de seguir uma vertente religiosa qualquer, e sim, algo superior em que estas acreditam e pedem força para superar as situações que vivenciam no dia a dia,com reais possibilidades de alcançarem melhores resultados, devido à inexistência de influências ou religiões diferentes, por exemplo.

Além disso, verifica-se quea abordagem dos aspectos religiosos e espirituais é essencial para o enfrentamento de situações estressoras, bem como diante das enfermidades do corpo e da alma, sobretudo porque as práticas religiosas e espirituais mostramse cada vez mais onipresentes no cotidiano de vida particular e social de grupos e de pessoas em diferentes sociedades, sendo capazes de propiciar um imbróglio de significados à mais diversificadas situações que se apresentam na vida cotidiana6.

Nessa perspectiva, encontram-se espaços para a inclusão da espiritualidade e religiosidade na assistência de enfermagem prestada a pacientes que vivenciam o processo de morte e morrer ${ }^{1,6,7,8}$. Na esfera paliativa, por exemplo, percebe-se que o paciente que recebe cuidados paliativos é um paciente sensível que tende a sentir maior carência espiritual e religiosa ${ }^{7,910}$. Isso conduz ao entendimento de que a postura do professional de enfermagem mediante essas circunstâncias é fundamental, pois na verdade, faz parte de uma grande categoria que dispende maior disponibilidade no cuidado que é prestado a esse grupo de pacientes e respectivos familiares, uma vez que passa mais tempo com esses usuários do que qualquer outro profissional da equipe multidisciplinar de saúde.

Portanto, o profissional de enfermagem, ao prestar a assistência em cuidados paliativos, depara-se com um paciente debilitado, frágil e ansioso, de tal modo que é necessário que fique atento a essas carências em sua prática $^{7,11}$, cabendo-lhe respeitar a história espiritual, os ritos e tradições do paciente, com a clareza de que seu papel não consiste em oferecer conselhos espirituais ou religiosos, mas fazer com que esse paciente encontre respostas para suas inquietações em suas próprias crenças ou até mesmo em sua descrença e o acolher da melhor forma possível, para que este possa se sentir mais preparado para enfrentar a o processo de morte e morrer.

Na literatura consultada, há endosso de que a estruturação da rede de cuidados paliativos ainda agoniza por políticas e ações mais eficazes para assegurar uma assistência alinhada com os princípios doutrinários e diretrizes do Sistema Único de Saúde ${ }^{12}$.

Dessa forma, ao agir com essa postura, o profissional de enfermagem pode contribuir para que o paciente consiga ter forças para enfrentar asdiversas situações que o desafiam em seu cotidiano exixtencial8, melhorando sua saúde mental, afastando os sinais de depressão, como também diminuindo o estresse, aceitando melhor e acreditando que suas atitudes definirão o seu final de vida, possivelmente com menor sofrimento e agonia. Logo, esseprofissional deve procurar um aprofundamento teórico ${ }^{13}$ sobre os valores espirituais e religiosos do paciente, para que juntos ampliem o leque de intervenções que tenham potencial para ajudá-lo nesse momento de tanta dificuldade,sendo esta uma forma de cuidado que avança para além do corpo físico e a ultrapassa, atingindo as nuances mais profundas e tangíveis da alma.

Diante desses apontamentos, é possível inferir e sugerir que, para o alcance de novas possibilidades de atuação, algumas intervenções podem ser utilizadas pelo enfermeiro para auxiliar a compreensão do contexto espiritual do paciente, tais como: leitura de textos religiosos, realização de orações, meditação, emprego de musicoterapia, reza, promoção de encontros com membros religiosos, dentre outros.

Da mesma forma,outras intervençõestambém podem ser implementadas pelos profissionais de enfermagem, utilizando uma abordagem espiritualizada, entre as quais também podem ser destacadas com maior profundidade o aconselhamento, intervenção esta definida pela Classificação das Intervenções de Enfermagem (NIC) como "o uso de um processo interativo de ajuda com foco nas necessidades, problemas ou sentimentos do paciente e de pessoas significativas para melhorar ou apoiar o enfrentamento, a resolução de problemas e as relações interpessoais" ${ }^{\prime 3}$.

Essas concepções encontram respaldo nas concepções defendidas por Jean Watson, cabendo então destacar que, tal como a teórica defendia, as intervenções espirituais podem ser desenvolvidas e se articularem ao aconselhamento, melhorando os resultados do tratamento de enfermagem.

Entretanto, para os profissionais de saúde, inclusive os de enfermagem, a abordagemde questões espirituais e religiosas, na prática dos cuidados paliativos, não constitui uma tarefa fácil, sobretudo porque eles possuem uma educação insuficiente a respeito do assunto e tambémporque falta-lhes tempo, privacidade e confiança para se empoderarem e se apropriarem desses referenciais ${ }^{4}$.

Considerandoessas constatações, fica evidente haver na atualidade justificativas relevantes para que essa realidade seja repensada e não mais negligenciada ${ }^{12}$, constatando-se que é urgente a necessidade das instituições formadorasinserirem temáticas relacionadas à espiritualidade e religiosidade nas unidades curriculares dos cursos de formação. Do mesmo modo, também é oportuno que as próprias instituições de saúde propiciem a criação de espaços para que os diversos profissionais 
possam ampliar o diálogo sobre essas questões que os desafiam no cotidiano da arte de cuidar,de modo que possam compartilhar suas experiências e se fortalecerem para auxiliarem outras pessoas a enfrentarem esse delicado momento que envolve a vida humana.

Acredita-se assim que, a partir dessas mudanças, possivelmente os profissionais de saúde, de modo geral, e principalmente os de enfermagem,possam adquirir e desenvolver maiores habilidades paraoferecer, através de seus cuidados, um tratamento mais humanizado, coerente e solidário àqueles que necessitam de sua ajuda, uma vez que muitos não possuem, inclusive, o apoio de suas famílias. Isso pode repercutir de maneira positiva sobre a condução da assistência, minimizando ao máximo o sofrimento que a premência e aproximação da finitude humana propicia ao ser que se reconhece morrendo lentamente.

Entretanto, há que se destacar que com a inserção da espiritualidade e da religiosidade, essa caminhadapode ser percorrida com menos sentimentos de abandono, vazio e dor ${ }^{1,6,7,8}$. A espiritualidade e a religiosidade, unidas ou separadamente, configuram fontes indiscutíveis para fortalecer e ampliar o potencial do cuidado e as relações entre quem cuida e quem é cuidado, constituindo formas de incontestáveis de apoio, expressão de fé, demonstração de crença, reafirmação de esperançae satisfação e de esclarecimento.

Nesse sentido, é imprescindível que se observe e que se ratifique também que para as pessoas que possuem um sistema de crenças religiosas, a espiritualidade pode oportunizar melhores respostas para suas questões existenciais. Da mesma forma, fazse necessário destacar que para as que não tem, isso não as torna menos importantes diante de grandiosidade de situações, necessidades e sentimentos vivenciados ao longo do processo em que facejam a aproximação da morte e do morrer, pois também carecem de conforto, solidariedade e da compaixão humana, condições implícitas e extremamente necessárias e profícuas para que ocorram a redução de seus anseios e medos associados à dor e ao sofrimento que a morte e o morrer suscitam.

Essas constatações ratificam que a inclusão da religiosidade e espiritualidade na assistência de enfermagem e de saúde em geral demonstram um grande impacto sobre a saúde física e mental de pacientes, familiares, cuidadores e profissionais que vivenciam a prática de cuidados paliativos ${ }^{1,6,7,8}$. Apesar de não haver solução para a morte, há de se destacar então que por meio da abordagem e inclusão de práticas assistenciais que valorizem a espiritualidade e a religiosidade, tornase possível ajudar ao próximo a morrer bem e com maior dignidade.

No que se reporta às implicações do estudo para a enfermagem, espera-se que possa contribuir para a pesquisa, ensino e assistência prestada por seus profissionais àqueles que se defrontam com a terminalidade e finitude devida. Isso, considerando que os argumentos levantados nesse breve debaterespectivamente, ampliam a produção científica existente sobre a temática e, ao mesmo tempo,podem despertar iniciativas para estimular outras reflexões e estudos, culminando com a construção de novos argumentos que se fazem necessários para a ocorrência de mudanças e a instituição de novas formas de pensar e fazer na esfera paliativa, com vistas à oferta de um cuidado efetivamente holístico e coerente com a essência humana.

\section{Conclusão}

O estudo buscou analisar a importância da associaçãodos cuidados em saúde coma empregabilidade de um olhar ampliado e mais humanizado, por meio da inclusão da espiritualidade e religiosidade na assistência de enfermagem prestada às pessoas que vivenciam o processo morte e morrer.

Dessa forma,conclui-se que apesar de não haver solução para a morte, é possível proporcionar um processo de terminalidade e finitude de vida dignos, para os quais são fundamentais o apoio emocional e a valorização da espiritualidade e da religiosidade no planejamento e implementação da assistência na ambiência paliativa. Nesse sentido, ratifica-se heuristicamente que a Enfermagem tem amplo potencial para minimizar o sofrimento e evitar o sentimento de abandono sofrido por pacientes sob cuidados paliativos, ao incluir em sua prática referenciais fundamentados na espiritualidade e religiosidade, oportunizando o bemestar e uma assistência com melhor qualidade e conforto, mediada pela ética, respeito, empatia e compreensão de todo esse processo, chancelando o seu compromisso com a sociedade, que clama por uma maior valorização da dignidade humana, da solidariedade, respeito e amor em tempos atuais.

\section{Referências}

1. Arrieira ICO, Thofehrn MB, Porto AR, Moura PMM, Martins CL, Jacondino MB. Espiritualidade nos cuidados paliativos: experiência vivida de uma equipe interdisciplinar. Revista Escola Enfermagem USP.[internet]. 2018 [citado em 12 de agosto de 2019]; 52: e03312: 1-8. Disponível em: http://www.scielo.br/pdf/reeusp/v52/0080-6234-reeusp-S1980220X2017007403312.pdf

2. CervelinAF,Kruse MHL. Espiritualidade e religiosidade nos cuidados paliativos: produzindo uma boa morte. Rev.Enferm UFPE Online. [internet].2015 [citado em 22 de Agosto de 2019]; 9(Supl.3): 7615-24. Disponívelem:https://periodicos.ufpe.br/revistas/revistaenfermagem/article/ view/10501

3. Mendonça AB, Pereira ER, Barreto BMF, Silva RMCRA. Aconselhamento e assistência espiritual a pacientes em quimioterapia: uma reflexão à luz da Teoria de Jean Watson. RevistaEscola Anna Nery 2018;22(4): 1-9.

4. Evangelista CB, Lopes MEL, Costa SFG, Abrão FMS, Batista PSS, Oliveira RC. Espiritualidade no cuidar de pacientes em cuidados paliativos: 
Um estudo com enfermeiros. RevistaEscola Anna Nery. 2016; 20(1): 176182

5. BreneSS, Costa EE,SilvaGabriel IGSP, Silva EA, Machado MR. Percepção de equipe de enfermagem sobre espiritualidade nos cuidados de final de vida. CogitareEnferm. 2016; 21(4): 01-08.

6. Alves DG, Assis MR.O desenvolvimento religioso e espirituale a saúde mental: discutindo alguns de seus significados. Conexões Psi.; 2015; 3(1): $72-100$.

7. Vieira AT, Oliveira M, Martins ERC, Costa CMA, Alves RN, Marta CB. Cuidado paliativo ao cliente oncológico: percepções do acadêmico de enfermagem. Revista de Pesquisa Cuidado é Fundamental Online[internet]. 2017 [citado em 12 de junho de 2019]; 9 (1): 175-80. Disponível em: http:// www.seer.unirio.br/index.php/cuidadofundamental/article/view/5329/pdf_1

8. Gomes, MP, Souza FBA, Gomes AMT, Silva FGA, Barbosa DJ, Silva ALB. Ressignificação da existência e do cotidiano. Revista Pró-UniverSUS. [internet]. 2019 [citado em 12 de agosto de 2019]; 10 (1): 2-6. Disponível em: http://editora.universidadedevassouras.edu.br/index.php/RPU/article/ view/1712

9. Silva DIS. Significados e práticas da espiritualidade no contexto dos cuidados paliativos em pacientes oncológicos adultos. Revista HCPA. 2011; 31(3): 353-8.

10. Evangelista CB, Lopes MEL, Costa SFG, Batista PSS, Batita JBV, Oliveira AMM. Cuidados paliativos e espiritualidade: revisão integrativa da literatura. Revista Brasileira de Enfermagem. 2016; 69(3):591-601.

11. Savieto RM, Leão ER. Assistência em enfermagem e Jean Watson: uma reflexão sobre a empatia. Revista. Escola Enfermagem Anna Nery. 2016; 20 (1):198-202.

12. Mendes EC, Vasconcellos LCF. Cuidados paliativos no câncer e os princípios doutrinários do SUS. Saúde Debate. 2015; 39 (106): 881-892.

13. Tonin L. Aplicação do modelo de cuidado transpessoal em enfermagem domiciliar às crianças com necessidades especiais de saúde e suas famílias [dissertação]. Curitiba: Universidade Federal do Paraná; 2018. 
Quadro 1. Bibliografia Potencial de Análise.

(continua)

\begin{tabular}{|c|c|c|c|}
\hline Título & Ano/ Revista & Objetivo & Conclusão \\
\hline $\begin{array}{l}\text { 1- Espiritualidade nos cuidados } \\
\text { paliativos: experiência vivida de uma } \\
\text { equipe interdisciplinar. }\end{array}$ & $\begin{array}{c}2018 \\
\text { Escola } \\
\text { Enfermagem } \\
\text { USP. }\end{array}$ & $\begin{array}{l}\text { Compreender a vivência da espiritualida de no } \\
\text { cotidiano de uma equipe interdisciplinar de cuidados } \\
\text { paliativos. }\end{array}$ & $\begin{array}{l}\text { Evidencia que a espiritualidade facilitaa a formação de } \\
\text { vínculos entre equipes, pacientes e familiares. }\end{array}$ \\
\hline $\begin{array}{l}\text { 2- Espiritualidade e religiosida de } \\
\text { nos cuidados paliativos: produzindo uma } \\
\text { boa morte. }\end{array}$ & $\begin{array}{l}2015 \mathrm{Rev} . \\
\text { Enferm. UFPE } \\
\text { Online }\end{array}$ & $\begin{array}{l}\text { Conhecer sobre a espiritualidade e religiosidade que } \\
\text { circulam nos livros sobre cuidados paliativos. }\end{array}$ & $\begin{array}{l}\text { O discurso dos livros se dirige a produzir uma boa morte, } \\
\text { destacando que a aceitação da morte e assistência } \\
\text { religiosa/espiritual são esssenciais. }\end{array}$ \\
\hline $\begin{array}{l}\text { 3- Aconselhamento e assistência } \\
\text { espiritual a pacientes em quimioterapia: } \\
\text { uma reflexão à luz da Teoria de Jean } \\
\text { Watson }\end{array}$ & $\begin{array}{c}2018 \\
\text { Rev. Escola } \\
\text { Enferm. Anna } \\
\text { Nery }\end{array}$ & $\begin{array}{l}\text { Refletir sobre o emprego de intervenções espinituais e } \\
\text { métodos de aconselhamento psicológico, teológico e } \\
\text { psicoterápico aplicáveis à enfermagem. }\end{array}$ & $\begin{array}{l}\text { A partir da Teoria de Jean Watson emergiu um } \\
\text { aconselhamento criativo, original e único na } \\
\text { enfermagem. }\end{array}$ \\
\hline $\begin{array}{l}\text { 4- Espiritualidade no cuidar de } \\
\text { pacientes em cuidados paliativos: um } \\
\text { estudo com enfermeiros. }\end{array}$ & $\begin{array}{c}2016 \\
\text { Rev. Escola } \\
\text { Enferm. Anna } \\
\text { Nery }\end{array}$ & $\begin{array}{l}\text { Compreender a espiritualidade sob o ponto de vista de } \\
\text { enfermeiros que cuidam de pacientes em regime de } \\
\text { cuidadospaliativos. }\end{array}$ & $\begin{array}{l}\text { Evidencia-se que os enfermeiros reconhecem a } \\
\text { importância da dimensão espiritual no atendimento de } \\
\text { pacientes sob cuidados paliativos. }\end{array}$ \\
\hline $\begin{array}{l}\text { 5- Percepção de equipe de } \\
\text { enfermagem sobre espiritualidade nos } \\
\text { cuidados de final de vida. }\end{array}$ & $\begin{array}{l}2016 \\
\text { Rev. Cogitare } \\
\text { Enferm. }\end{array}$ & $\begin{array}{l}\text { Investigar a percepção da equipe de enfermagem } \\
\text { acerca da espiritualidade nos cuida dos de final de vida. }\end{array}$ & $\begin{array}{l}\text { Toma-se necessánia a inclusão do tema espiritualidade } \\
\text { nos currículos das instituições de nível superior como } \\
\text { forma de sensibilização e capacitação dos profissionais. }\end{array}$ \\
\hline $\begin{array}{l}\text { 6- O desenvolvimento religioso e } \\
\text { espiritual e a saúde mental: discutindo } \\
\text { alguns de seus significados }\end{array}$ & $\begin{array}{l}2015 \\
\text { Rev. Conexões } \\
\text { Psi. }\end{array}$ & $\begin{array}{l}\text { Investigar de forma concisa, a relação da religiosidade } \\
\text { e da espiritualidade com a saúde mental dos indivíduos. }\end{array}$ & $\begin{array}{l}\text { Verificou - -se que a religiosidade e a espiritualidade são } \\
\text { fatores e dimensões da vida humana que não podem ser } \\
\text { desconsideradas, pois podem constituir um fator } \\
\text { relevante no equilíbrio de suas funções psíquicas. }\end{array}$ \\
\hline $\begin{array}{l}\text { 7- Cuidado paliativo ao cliente } \\
\text { oncológico: percepções do aca dêmico de } \\
\text { enfermagem. }\end{array}$ & $\begin{array}{l}2017 \\
\text { Rev. Pesquisa. } \\
\text { Cuidade é } \\
\text { Fundamental } \\
\text { Online }\end{array}$ & $\begin{array}{l}\text { Identificar o saber dos aca dêmicos de enfermagem com } \\
\text { relação aos cuidados paliativos e discutir o diferencial } \\
\text { deste profissional para a qualida de do cuidar ao cliente } \\
\text { oncológico. }\end{array}$ & $\begin{array}{l}\text { Acredita-se que a boa prática deve ser resulta do de muita } \\
\text { dedicação, de busca por conhecimentos científicos e, } \\
\text { principalmente, pelo fortalecimento do ser humano que } \\
\text { existe em cada profissional. }\end{array}$ \\
\hline
\end{tabular}


Quadro 1. Bibliografia Potencial de Análise.

(continuação)

\begin{tabular}{|c|c|c|c|}
\hline $\begin{array}{l}\text { 8- Ressignificação da existência e } \\
\text { do cotidiano. }\end{array}$ & $\begin{array}{l}2019 \\
\text { Rev. Pró- } \\
\text { UniverSUS. }\end{array}$ & $\begin{array}{l}\text { Analisar como os sujeitos ressignificam o cotidiano } \\
\text { buscando a continuidade. }\end{array}$ & $\begin{array}{l}\text { Conclui-se que os sujeitos ressignificam a vivência do } \\
\text { cotidiano amparados no trabalho na rede social de apoio } \\
\text { e em elementos que expressam religiosidade/ } \\
\text { espiritualidade. }\end{array}$ \\
\hline $\begin{array}{l}\text { 9- Significados e práticas da } \\
\text { espiritualidade no contexto dos cuidados } \\
\text { paliativos em pacientes oncológicos } \\
\text { adultos. }\end{array}$ & $\begin{array}{c}2011 \\
\text { Rev. HCPA. }\end{array}$ & $\begin{array}{l}\text { Conhecer os significa dos e práticas da espiritualidade } \\
\text { para os pacientes oncológicos a dultos, enfermeiros e } \\
\text { familia no contexto dos cuidados paliativos. }\end{array}$ & $\begin{array}{l}\text { Conclui-se que a espiritualidade pode ajudar pacientes, } \\
\text { familiares, enfermeiros e demais profissionais a } \\
\text { enfrentarem melhor as situações de iminência de fim da } \\
\text { vida ou mesmo a morte em si. }\end{array}$ \\
\hline $\begin{array}{l}\text { 10- Cuidados paliativose } \\
\text { espiritualidade: revisão integrativa da } \\
\text { literatura. }\end{array}$ & $\begin{array}{l}2016 \\
\text { Rev. Brasileira de } \\
\text { Enfermagem. }\end{array}$ & $\begin{array}{l}\text { Analisar artigos científicos dissemina dos em periódicos } \\
\text { online no cenánio intemacional acerca da temática. } \\
\text { suidados paliativos e espiritualidade. }\end{array}$ & $\begin{array}{l}\text { Verificou-se a relevância da dimensão espiritual durante } \\
\text { a assistência de pacientes assistidos, para } \\
\text { desenvolvimento de novos estudos para disseminar } \\
\text { conhecimento sobre o tema. }\end{array}$ \\
\hline $\begin{array}{l}\text { 11- Assistência em enfermagem e Jean } \\
\text { Watson: uma reflexão sobre a } \\
\text { empatia. }\end{array}$ & $\begin{array}{l}2016 \\
\text { Rev. Escola } \\
\text { Enfermagem } \\
\text { Anna Nery } \\
\end{array}$ & $\begin{array}{l}\text { Relacionar a empatia com a Teoria do Cuidado } \\
\text { Humano de Jean Watson no contexto atual da } \\
\text { Enfermagem. }\end{array}$ & $\begin{array}{l}\text { Entende-se que essa reflexão pode contribuir para a } \\
\text { reorganização de ideias e conceitos sobre } \\
\text { aprimoramentos essenciais que se mostramnecessánios à } \\
\text { prática atual da Enfermagem. }\end{array}$ \\
\hline $\begin{array}{l}\text { 12- Cuidados paliativos no câncer e os } \\
\text { princípios doutrinánios do SUS. }\end{array}$ & $\begin{array}{l}2015 \\
\text { Rev. Saúde } \\
\text { Debate. }\end{array}$ & $\begin{array}{l}\text { Analisar a relação entre os cuida dos paliativos e os } \\
\text { princípios doutrinánios do SUS }\end{array}$ & $\begin{array}{l}\text { Conclui-se que a estruturação da rede de cuidados } \\
\text { paliativos carece de eficácia para o seu desenvolvimento, } \\
\text { enquanto política pública coerente com a doutrina do } \\
\text { SUS. }\end{array}$ \\
\hline $\begin{array}{l}\text { 13- Aplicação do modelo de cuidado } \\
\text { transpessoal em enfermagem } \\
\text { domiciliar às crianças com } \\
\text { necessidades especiais de saúde e } \\
\text { suas famílias [dissertação]. } \\
\end{array}$ & $\begin{array}{c}2018 \\
\text { Universidade } \\
\text { Federal do Paraná }\end{array}$ & $\begin{array}{l}\text { Desenvolver uma teoria substantiva representativa da } \\
\text { vivência do cuida do domiciliar e propor ações para a } \\
\text { prática de enfermagem que conduzam à interação } \\
\text { transpesşal com o paciente. }\end{array}$ & $\begin{array}{l}\text { Espera-se que esse estudo possa contribuir para o } \\
\text { desenvolvimento da profissão e avanço do saber em } \\
\text { Enfermagem, em especial, da Enfermagem domiciliar. }\end{array}$ \\
\hline $\begin{array}{l}\text { 14- Aplicação do modelo de cuida do } \\
\text { transpesssoal em enfermagem } \\
\text { domiciliar às crianças com } \\
\text { necessidades especiais de saúde e } \\
\text { suas familias [dissertação]. }\end{array}$ & $\begin{array}{c}2018 \\
\text { Universidade } \\
\text { Federal do Paraná }\end{array}$ & $\begin{array}{l}\text { Desenvolver uma teoria substantiva representativa da } \\
\text { vivência do cuida do domiciliar e propor ações para a } \\
\text { prática de enfermagem que conduzam à interação } \\
\text { transpessoal com o paciente. }\end{array}$ & $\begin{array}{l}\text { Espera-se que esse estudo possa contribuir para o } \\
\text { desenvolvimento da profissão e avanço do saber em } \\
\text { Enfermagem, em especial, da Enfermagem domiciliar. }\end{array}$ \\
\hline
\end{tabular}

